
\title{
R Research Square \\ Community Nurse-Paramedics' Sphere of Practice in Primary Care; an ethnographic study
}

\section{Tuija Rasku ( $\boldsymbol{\sim}$ Tuija.Rasku@tuni.fi )}

Tampereen Yliopisto https://orcid.org/0000-0001-8964-1936

\section{Marja Kaunonen \\ Tampereen Yliopisto}

\section{Elizbeth Thyer}

Western Sydney University

\section{Eija Paavilainen}

Tampereen Yliopisto

\section{Katja Joronen}

Turun Yliopisto

\section{Research article}

Keywords: Health Services, Primary health care, Community paramedicine, the sphere of practice

Posted Date: November 6th, 2020

DOI: https://doi.org/10.21203/rs.3.rs-63965/v1

License: (c) (i) This work is licensed under a Creative Commons Attribution 4.0 International License. Read Full License

Version of Record: A version of this preprint was published at BMC Health Services Research on July 18th, 2021. See the published version at https://doi.org/10.1186/s12913-021-06691-y. 


\section{Abstract \\ Background}

Primary care, the principal function of the healthcare system, needs efforts from the local primary healthcare teams. Community Paramedicine has managed to reduce the use of Emergency Medical Services (EMS) for non-emergent calls. For the paramedic to move from traditional emergency call outs to non-emergency care means new demands. There is a paucity of paramedics' experiences and perceptions of their novel roles as community paramedics. This study aimed to explore the community nurse-paramedics experiences of their new sphere of practice.

\section{Methods}

A descriptive ethnographic research was conducted collecting data through participant observation (total 317 hours) and semi-structured interviews $(N=24)$ in three Hospital Districts where the community nurseparamedics (CNP) have worked at least one year. Both data were combined, organized, and analyzed with inductive content analysis.

\section{Results}

From the inductive content analysis, five themes emerged: the CNP's new way of thinking, the broad group of patients, the demanding way to provide care, the diversity of multi-agency collaboration and management challenges. The CNP needs an appropriate attitude for the care and the broader way of thinking than before, taking care of the patient but also about the family members. The CNPs pointed out as enablers for the way of providing care as challenges for the management of the CNP model. The diversity of multiagency collaboration team can be sensitive while offering new possibilities.

\section{Conclusion}

The CNP's deep involvement in patients' and families' care needs and the challenges of CNPs' skills and competences. Their professional attitudes and eagerness to develop and maintain the multi-agency collaboration can offer preventive and long-term caring solutions from which the citizens and allied health, safety, and social care providers benefit locally and globally.

\section{Background}

According to WHO (1), Primary Care has the central focus and principal function of the healthcare system. It is the first contact care, and its providers are expected to be comprehensive, and the care needs to be coordinated. Primary Care is person-focused (not disease-oriented) provided to individuals and as close to the user as possible. Diseases are considered medical, psychological, and social problems. The 
national primary care strategies need efforts from the local primary health care teams; front-line realities. Continuity is the coherence of primary care. The health services are tailored to the needs of the population, contributing to the comprehensiveness of care (2). There is an urgent need to create new healthcare models in the primary care setting to decrease the pressure on the home-care workers $(3,4)$

Internationally, community paramedicine is community-engaged, patient-centered preventive care, including multi-agency collaboration, and has many forms of programs as an integrated part of the primary care setting (5). To work as a community paramedic means that the paramedic steps out from the traditional emergency role providing patient assessment and non-emergency care with allied prehospital health care providers. In the future, many health care providers' roles might change, and the needed competencies could be broader, whereas the care should remain qualitative and safe $(4,6)$.

In endeavoring to follow these changes, there is an increased demand placed on primary health care, which leads to a greater need for allied health professionals to carry out assessments and treatment traditionally delivered by physicians (7). In some prehospital jurisdictions, paramedics work seamlessly with the allied health care professions, providing to patients well-organized and high-quality care. (4-6, 8-11).

Globally, Community paramedicine (CP) programs have filled the local healthcare delivery gaps and assessed the patient's possibilities to remain at home. The community paramedic assesses the patient, takes an advanced blood test, analyzes ECG, arranges the referral direct to x-ray or for the follow-up visit, assists with the medication management, or arranges the social support $(7,12,13)$. They have been supported through protocols or directed online (telephone or video) by different physicians, e.g., geriatricians, general internists, family practitioners, paediatricians, or emergency physicians (14). The reports and evaluations of CP programs have underpinned the need for the organizational support, longterm planning of the multi-agency collaboration and challenges for the economy, or the reimbursement of this health care service $(14,15)$.

The Finnish Government legislates customer-oriented and supportive health care services (16). In their proposal, the one-person EMS units could provide non-emergency patient assessment and small treatments beyond ambulance units' emergency services. These one-person Finnish EMS units are comparable to Community Paramedicine units around the world. In Finland, EMS staff are mostly nurseparamedics, who are registered as nurses and work under the direct supervision of the EMS physician of the HD. (17) Finnish community nurse-paramedics have long experiences in an emergency or prehospital nursing and have undertaken additional training. Their role has developed in response to the shortage of health care providers in primary care and with the awareness of their independent skills with the patient assessment in challenging circumstances.

Generally, the paramedics' role and the demands of competences have changed from traditional views. In a previous study, paramedics got many different roles like a clinician, team member, health and social advocate, educator, reflective practitioner, and professional. These roles were linked with patient safety, compassion, adaptability, and communication $(12,18)$. There is a paucity of paramedics' experiences 
and perceptions of their novel roles as community paramedics; has something changed in their sphere of practice since working in the ambulance unit. By conducting an ethnographic study in a CNPs' context, we aim to identify and explore the actions, experiences, and perceptions of Finnish CNP's sphere of practice. By analyzing CNPs' responses, we add the growing body of research into Community Paramedicine, contribute clarity to the possibilities, demands, and sustainability of this health care model and provide foundational knowledge for future use to policymakers and health care providers, and educators.

\section{Methods}

\section{Methodology}

The study aimed to explore the Finnish nurse-paramedics' experiences and perceptions of their work as community nurse-paramedics. We used an ethnographical research frame because ethnography aims to deepen the understanding of social phenomena in a social setting (19-21), and the ethnographic approach is especially recommended during cultural changes from one stage to another (22). We wanted to understand what Finnish CNPs are doing and how they have experienced the changes from a nurseparamedic to a CNP. Ethnographic research orientation includes fieldwork, the position of the researcher, and the purpose of the study. The researcher is the essential research "device" when the researcher is personally among the participants (21). Our study design for data collection included participant observation and semi-structured interviews. When taking part in people's lives, listening to the informants' words and the interpretation of action, we could collect thick description (19), meaning that the researcher reflects social events and actions, and the description and analysis root in reality. Participant observation is the recommended method for gaining an in-depth understanding of a phenomenon $(19,20)$. It revealed nuances from the CNPs' daily work, which would not have come to light in interviews alone (23). The researcher needs to understand the participants' perceptions (emic), which helps to uncover knowledge of the reasons for participants' acting. Health researchers have used more the outsider's perspective (the etic view) when trying to identify and describe patients' problems instead of listening to the patients' ('illness experts') own ideas of their condition, feelings, and perceptions. In the ethnographic study, both views, emic, and etic are needed. They summarize the insights and words of the participant into the language of science (21). Ethics approval was obtained from Tampere University Hospital Ethics Committee (Approval $\mathrm{R} 19008 \mathrm{H})$.

\section{Study setting}

Finland is divided into 21 Hospital Districts (HD) to provide specialized medical care. Every municipality belongs to one of the hospital districts. Each hospital district has a central hospital and municipal healthcare center associated with one of five university hospitals. The research was undertaken in three HDs where CNP-model has provided non-emergency health care services with allied health care and safety workers as the polices and the safety alarm responders. The size of the HDs was similar (inhabitants from $130000-190$ 000, areas between $7000-22000 \mathrm{~km}^{2}$ ). These HDs were selected 
purposely because the CNP model had been running for at least one year. The CNP model includes 1-2 units staffed with nurse-paramedics who have had further training.

\section{Participants}

\section{Data collection}

During the same summer, the observation happened in all HDs by one researcher (TR) to mitigate bias's inherent threat. Within each HD, three sources of data were collected and analyzed:

\section{Participant observation of CNPs'}

2. Semi-structured interviews of $21 \mathrm{CNPs}$ and allied health care providers

3. Interactions with other health staff and patients

This multi-method approach captured the diversity of the CP models within its natural setting and allowed issues to be studied in-depth.

For the observational period, the participants, patients, and family members were made aware of the study's purpose, the researcher's role, and reminded that they would be anonymous in the data. TR also made it clear that each participant could withdraw at any time. When visiting the patient, the CNP asked from the patient (or from the family member or the home care nurse if the patient was not able to speak or understand the question) if the researcher can stay. The patient or the CNP could deny the researcher's presence at any time. The researcher did not take part in the interventions. The observational period included CNPs call outs as the patient assessment by phone or by visit, training sessions for other health care providers, meetings with allied health care workers, and cooperation with police and safety alarm providers.

The principal researcher spent between two to five 10-12-hour shifts with each CNP. Between two CNPshifts, there was one day-off, when the researcher transcript the field notes and the interview. Afterward, during the second round, the researcher went back to the interviewees to confirm the findings. The observational notes and transcript were read and discussed with the research team members to ensure the consistency of interpretation.

The researcher kept the field diary, where contemporaneous descriptions were extended and detailed after each workday. Informal discussions with CNPs were an essential component of the observation part of the data collection process. During the observation, the researcher noted CNPs practice immediately after patient calls, along with CNPs' comments.

The observational data were completed with the semi-structured interviews. The interview guide (Figure 1) ensures that the researcher collects similar data from all informants and gain the informants' perspectives. 
Questions were piloted in three interviews (two CNPs and one nurse-paramedic) to assess clarity and potentials bias. No changes were needed. The rest of the interviewees were conducted with 11 CNPs. The data were enriched by interviewing four nurse-paramedics, five EMS team leaders or field managers, and one care coordinator $(\mathrm{N}=21)$, who were selected after initial CNP interviews to add to the identified themes.

Interviews undertaken were a mix of formal, during a dedicated period away from the shift, or informal, during the breaks, a common practice in ethnographic research (21). Four of the CNPs and two of the team-leaders (involved with CNP model) were on holiday, and because of the distances, they were interviewed by phone. Formal interviews were audio-recorded and later transcribed verbatim, whereas informal interviews sometimes evolved from conversations and were recorded through contemporaneous notes and further description immediately after the interview. In both cases, interviewees were provided with the 'transcript' of the interview to review, consider, and amend. The interviewees approved the interview transcripts as a full and completer record of the interview.

The data were organized; the fieldnotes were sorted, and the interviews were transcribed. The transcripts were checked with the interviewees during the next work shift, and the corrections were made if needed (21). Then all transcripts were anonymized and stored in a password-protected database.

\section{Data analysis}

Data from both methods were combined and analyzed using inductive content analysis. The inductive content analysis process includes open coding, coding sheets, grouping, categorization, and abstraction (24). (Figure 2).

When the words and phrases are classified into the same categories, they share the same meaning (25). With open coding, the notes and headings were written in the text while reading it. The written material was read through three times by TR to avoid the risk of focusing overly on the parts of the data. In the margins, new headings were written down to describe aspects of the content. Thus, the researcher did not lose sight of the meaning and depth of findings (21).

The meaning of the data was continuously reflected, which allows the codes to emerge from the data. Then the second author $(\mathrm{KJ})$ joined the analysis, with no prior knowledge of the data. From the original expressions were created open codes $(\mathrm{N}=213)$. The codes were colored to identify closely linked material. Table 1 presents an example of the inductive content analysis process.

Table 1. Example data extracts demonstrating the hierarchical coding process 


\begin{tabular}{|c|c|c|c|c|}
\hline Original text & Open codes & $\begin{array}{l}\text { Sub- } \\
\text { cateory }\end{array}$ & $\begin{array}{l}\text { Generic } \\
\text { category }\end{array}$ & $\begin{array}{l}\text { Main } \\
\text { Category }\end{array}$ \\
\hline $\begin{array}{l}\text { "..it is important, that you sit down with } \\
\text { the patient and the family members and } \\
\text { try to find the solution which I think } \\
\text { means that there is some long-term plan } \\
\text { for the person to survey at home..." }\end{array}$ & $\begin{array}{l}\text { sitting down } \\
\text { with the } \\
\text { patient and the } \\
\text { family } \\
\text { finding the } \\
\text { solution } \\
\text { making the } \\
\text { long-term plan } \\
\text { comprehensive } \\
\text { survey at } \\
\text { home }\end{array}$ & $\begin{array}{l}\text { time to } \\
\text { sit } \\
\text { patient \& } \\
\text { family } \\
\text { solutions } \\
\text { long- } \\
\text { term } \\
\text { planning } \\
\\
\text { survey at } \\
\text { home }\end{array}$ & $\begin{array}{l}\text { one tool to } \\
\text { achieve the } \\
\text { aim } \\
\text { together } \\
\text { with patient } \\
\& \text { family } \\
\text { the aim of } \\
\text { the } \\
\text { assessment } \\
\text { the aim of } \\
\text { the } \\
\text { assessment } \\
\text { the aim of } \\
\text { the care }\end{array}$ & $\begin{array}{l}\text { The } \\
\text { broad } \\
\text { way of } \\
\text { providing } \\
\text { care }\end{array}$ \\
\hline
\end{tabular}

Three researchers were the coders and frequently discussed the coding process and clarified any disagreements on the codes. The codes were grouping to sub-categories $(\mathrm{N}=56)$, meaning to provide a means of describing the phenomenon (25). The material was clear, and no software was used to manage the data.

Each sub-category was named using content-characteristic words creating generic categories $(N=13)$. By using the abstraction, the data emerged five main categories (24). Any inconsistencies were resolved by joint review and discussion. Authentic citations are used to increase the research's trustworthiness and determine what kinds of original data categories are formulated (26).

\section{Results}

In total, 24 health care professionals participated (three took part in pre-study and 21 were interviewed) in this study, of which 11 were females and ten males. From the participants, 13 were community nurseparamedics, five nurse-paramedics, five EMS team leaders or field managers, and one care-coordinator from three HDs across Finland. The participants had all worked longer than five years as health care providers and since the beginning of the local CNP model. The field period was a total of 317 hours, which provide a 'thick description' of the research site (19). During the field period, the researcher observed nine CNPs' work during 94 patient assessments. 
Data from both the interviews and observational field notes produced 213 open codes, categorized to 56 sub-categories and then to 13 generic categories. The initially identified categories were reduced, and from the inductive content, analysis emerged five main categories: (1) The CNPs' new way of thinking, (2) The broad group of patients, (3) The demanding way of providing care, (4) The diversity of multi-agency collaboration, and (5) Management challenges (Figure 3). Each theme included coded quotations to illustrate the findings.

\section{The new way of thinking}

The new way of thinking includes sub-categories, an Appropriate attitude, and Thinking on the second level. The interviewees articulated that the CNP needs an appropriate attitude for the care, meaning that the CNP is not seeking "lights and sirens" and is voluntarily engaged in the new role. With the "thinking on the second level," comments indicated that CNPs do not think differently but broader than before.

The CNP got a phone call where the home care assistant was worried about the client's low level of blood pressure. The 92-years old lady lives alone. The CNP read from the hospital records that the level of blood pressure is average for the lady. After the patient assessment, the CNP decided that the patient can stay at home. The lady wants to go to a shop. The CNP advised that the lady not go to the shop, even if the fridge is empty. (The home care assistant checked it). The CNP asked the lady to stay at home and called the Meals-on-the-Wheals -service. They checked that the lady is their customer. The lady has refused their help earlier. Now she promised to open the door for the food delivery. Home Care assistant promised to make an extra visit to the lady in the evening. (Excerpt 1, Observational notes)

The interviewed articulated that the most significant risk is if the CNP behaves wrongly. It could destroy, for various reasons, the relationship between the patient and the family and the relationships in the multiagency collaboration team.

Not all of us can work as community nurse-paramedic. This job is for you when you do not get kicks anymore from the lights and sirens. You must be ready to concentrate on the patient and the family for a longer time than before. In the beginning, it could be very hard. (Excerpt 2, CNP)

\section{The broad group of patients}

The interviewed CNPs characterized the broader group of patients with New groups of patients and care of carers. They underpinned that most of their patients are old and live either very lonely or with even older or frailty spouse. The interviewees described that as a new group of patients, there are more often palliative care patients with different ages, patients from elderly care homes, or discharged patients with minor treatments. The CNPs felt that behind many physical considerations is the need for social support.

All our patients are not clients of home care. Discharged patient's wound could be open and secret, but the patient does not have any pain medication or is to scare to clean the wound or even go to the shower...the spouse can be very scared, do not sleep at all. If we are not visiting there, we (EMS) might 
have two patients in the morning. During our visit, we try to explain what "spray the wound " or "take a painkiller when needed" means. (Excerpt 3, CNP)

We visited a male patient in the elderly care home. He has been very drowsy during dinner. The CNP assessed the patient and took the urine sample and read from the patient's history that he has had a couple of urine infections before. The sample showed an infection again. The CNP called to the doctoron-call in the local health care center about the permit to start the antibiotic medication for the patient. The doctor agreed, and the client felt much better in the evening when the CNP made the checking call. (Excerpt 4, Observational notes)

The CNPs can deliver advanced diagnostic, and they have received additional education on palliative care. With these patients, the CNPs help the home care nurses mostly during nights and weekends. The patients have a direct number to the CNP-unit, and either they or the family members know that they can call whenever they want to $24 / 7$.

On Christmas Eve, I called direct to the palliative care physician. We decided so that the patient could stay at home over Christmas with the family and did not need the transportation to the hospital for the change of the medication. The family was pleased with this arrangement. (Excerpt 5, CNP)

First, we feared how the CNPs handle palliative care patients, but in the end, it is infrequent that the family calls. I think the most important information for the family is that they have a direct line to a person who knows them and their situation at home. (Excerpt 6, EMS team leader)

The CNP model has got much thankful feedback from families when the patients can avoid the uncomfortable travel to the ED and back, e.g., just to control the PCA (patient-controlled analgesia)-pump. The CNPs felt that during these mutual relationships between the patients and the families, they get more direct and positive feedback.

I see more smiles than before. The patients and the families are relieved to remain at home. If I had eaten all that chocolate and cakes, what these grateful patients or family members are offering I would be 30 kg heavier. (Excerpt 7, CNP)

The CNPs noted that their job does not end after the ambulance has taken the patient to the ED. The CNPs' job is also to care for the spouse, and CNP needs to find the solution to how the spouse surveys at home while the patient is in hospital. Sometimes the "healthier" spouse needs transportation to the hospital, and the CNP starts to find the right place for the weaker life-partner.

The spouse was taken to the hospital, and I saw that the wife was very pale. I sat down with her and asked how she is coping. She started to cry and told me that she is fatigued. They did not have anyone to come, so I managed to get a temporary place for her to rest. Before this CNP-model, we would have taken the husband to the hospital and just wished that the wife will cope at home. (Excerpt 8, CNP)

\section{The demanding way of providing care}


The interviewees described CNP's way of providing care with new roles as an advocate or navigator, loneliness of the work, former skills and new competences, the luxury of time, possibilities for long-term effects, and job-rotation.

In their new roles as patients' and families' advocates or navigators, the CNPs described that their assessment could start already from the front yard. CNP makes calls to other health care providers trying to speak for the patient or the family. They felt that they need to be innovators, developers, therapists, and repairers while working as healthcare professionals and clinicians.

The main thing is not to fix the patient; we like to connect them to the right place to the right people. One idea could be day-care visiting clubs for older adults to see other people because so many are just lonely. (Excerpt 9, CNP)

However, after patient assessment, they try to navigate the patient the best path in the fragmented healthcare system.

The CNP's work is very independent, but with that comes the loneliness, which could be very hard in the beginning. CNP works alone and makes the decisions or tells the poor test results facing the sadness and disappointment besides the patient and the family - at their home.

The CNP must be ready to make the right decision and make it there, in front of the family and alone. It is challenging to make an accurate patient assessment with incomplete information about the patient's condition. This job has its loneliness. When you worked as a nurse-paramedic, you can talk with your partner during the assessment or immediately afterward, but now you are alone. For the consultation, the doctor is in the hospital, not there in front of the eyes of a little child and talking about the parent and maybe destroy their trip to the zoo. (Excerpt 10, CNP)

The interviewed CNPs pointed out that they have four years of education to become nurse-paramedic and registered nurses. After three years of nursing studies, they specialize in prehospital emergency care. While working as a nurse-paramedic, the focus is on patient assessment and managing the patient's lifethreatening conditions. However, the interviewed CNPs felt that there is a more significant demand for rehearsing former nursing skills. At the same time, they apply new skills and competencies like falls risks, nutrition, or sepsis assessment, and antibiotic administration.

I have not used some nursing skills since school, like wound therapy or urine catheterization in years. Now we need to practice them. Another challenge is that we have excellent blood test machines, but we need to understand more than just the numbers given to us. (Excerpt 11, CNP)

Nowadays, we work as the right partner with the police patrol. They do not take the driver to the ED for the drug blood-test. They call us, and we meet at the police station. The guardian is there with us, and the patrol is free to go back for their real job. If these people are taken to ED, as in the old days, they can be restless and noisy, it is a safety mater also, you know. (Excerpt 12, CNP) 
The interviewed underpinned that another new competence is the patient assessment by phone. While they worked as nurse-paramedics, they got the call out from the dispatch center and went to the patient. However, now the CNP uses the phone more often for the patient assessment with the Home Care, consulting different physicians, and arranging further care or finding general information from health and social care networks.

Today we had only one visit to the patient, but all day the CNP got phone calls. Most of the calls came from home care, and the CNP gave them advice, contact numbers, or organized appointment into the Health Care Center or from the home doctor. Some phone calls sounded more like coaching the family member to cope with the patient. (Excerpt 13, Observational notes)

The CNPs articulated that the most positive add and an enabler to provide care is the luxury of time. They can sit down, talk with the patient, and there is no need to rush. Time enables them to get a more holistic picture of the patient and the family and find and make solutions with long-term effects.

It is peaceful to sit down on the sofa and discuss the solutions and challenges with the whole family. It gives me a deeper meaning of our work if we try to find a solution for tomorrow. (Excerpt 14, CNP)

The interviewed indicated a desire to use a job-rotation with their former skills and new competencies in both scopes of practices, with emergency cases and in non-emergency assessments. They were concerned about how to maintain all these more extensive skills and competences.

The job-rotation in the CNP-unit and the ambulance unit is excellent; so, I can keep my touch with the emergencies and with these more like psycho-social-physiological CNP -visits. (Excerpt 15, CNP)

\section{The diversity of multi-agency collaboration}

The interviewees described the diverse of their multi-agency collaboration with New team members, Learning from other professions, and sensitiveness of collaboration.

The CNP works more intensively with other health care providers and police than before and is planning the patients' future with the patient and the family. The familiar team members were the home care providers, police, safety alarm responders, and emergency doctors. However, now as the CNP, the work was closer with the home care providers, and with the new team members as the psychiatric nurses, and the other specialized doctors than an emergency doctor-on-call.

Today -yes, it is a full moon - we visited two patients with psychiatric problems. We picked up the psychiatric nurse from ED, and I admired how he and the CNP worked together with the patient. Before we left, both patients found the solution for them and did not need transportation to the ED. The CNP and the psychiatric nurse had very long discussions while we were driving back. It was a multi-agency collaboration as its best. (Excerpt 16, Observation notes) 
As cooperation with ambulance staff, the CNP called the patient and received further information about the patient's situation or medical history to be given further to the coming ambulance unit.

When the CNP calls us the patient's advanced information and medical history, it is much safer for us to go to the patient, and we have more history of working with." (Excerpt 17, Nurse-Paramedic)

The CNPs preferred to help home care nurses consult the geriatric or the General Practitioner from the local Health Center.

Many of our patients have a long medical history and chronic diseases - it is better to consult directly with the doctor who already knows the patient or is specialized in that disease. (Excerpt 18, CNP)

The CNP works together with home care nurses, and both have an education in nursing skills. CNP needs former nursing skills.

Today was quiet. The CNP asked do I want to follow him to the hospital laboratory. There we got information about the new blood-test machine. From there, we went to the health care center, where the CNP kept a training session of CPR for the ward nurses. Yesterday we were there in the same ward, but then, one of the nurses showed us how the painkiller pump could be restarted. (Excerpt 19, Observational notes)

If the phone's assessment included the information that the patient might have the mental problems, the CNP could pick up the psychiatric nurse from ED and then assess it at home. The interviewed CNPs underlined that then both are learning from each other. The CNPs' cooperation with the police involved taking the alcohol or drug blood samples from the suspect drunken driver or taking care of the medication administration when the citizen is as remand.

The interviewees spoke about the sensitiveness of the collaboration when the rumors and misunderstandings could easily harm the multi-agency cooperation. Some respondents were concerned about how allied health care providers would react or if they feel threatened by this new CNPs' scope of practice.

This new cooperation is compassionate. In the beginning, some should do proper informing kind of marketing of us, telling who we are and what we do - the rumors can harm a lot. Our coworkers could be scared and make the assumptions too easily. (Excerpt 20, CNP)

\section{Management challenges}

The CNPs indicated that being able to navigate the fragmented healthcare system requires clearance and support from the management. Other challenges in the system of community paramedicine were the planning of the model, the local CNP model's economy, organization of the model, unclear reimbursement of the service, and adequate coding from the dispatch center. The patients' health information has a lack 
of common information platform, which has the risk that the information can be inaccurate, and it is not available for the CNPs' planning and decision of the patient's possibilities to remain at home.

This CNP model provides excellent help, but the management does not always understand what we are doing, or, e.g., the reimbursement system is too much with the old EMS way. (Excerpt 21, CNP)

If the code from Dispatch Center is D (David = the patient should be reached in two

hours), would you like if your grandmother lies on the floor two hours waiting for

help. (Excerpt 22, CNP)

\section{Discussion}

This study explored the experiences and perceptions of the Finnish CNPs' with their Community Paramedicine care and identified critical vital elements: (1) the CNPs' attitude needs to be appropriate, and the way of thinking needs a new level, (2) the group of patients is added with the carer or family member, (3) the CNPs' possibilities to provide care are broad, (4) the diversity of multi-agency collaboration can be sensitivity and (5) management of the model has its challenges. Our findings fill the literature gap, how community paramedicine providers, themselves, perceived their work; "What has changed since working in an ambulance unit; has something changed?".

In this study, we found that the core of the CNP's new way of thinking was the appropriate attitude of the non-emergency care and the ability to think broader than before: "on the second level." A recent study examining the paramedics' willingness to participate in the Community Paramedicine model of care supports the findings of this research that not all paramedics want or should become Community Paramedics $(27,28)$. The willingness to participate in a CP program should impact when the new participant nurse-paramedics are selected. The interviewed CNPs highlighted the excellent interpersonal skills and the long experience in their work competences.

Steeps et al. (27) found that most of the EMTs or paramedics were willing to attend additional education to offer CP services. The tailored further education for Community Paramedics has included, e.g., coaching and communication subjects $(14,28,29)$. Our results are consistent with these findings. The nurse-paramedics are already well trained to perform patient assessment and to recognize and manage life-threatening conditions. Now the new way of thinking includes settling down, concentrating, and navigating in the middle of health and social care puzzle with time and very close the patient and the family, which creates the need to change the focus of thoughts wider than before. In contrast to a biomedical focus, the CNPs' need to turn the thinking from the system thinking to responsible thinking and use the innovations, experiences, and creativeness while finding the holistic and long-term solutions for the patients' and their families' health and social needs.

Our results indicated that the broad group of CNPS' patients includes mostly elderly and multimorbidity patients from homes or elderly care homes. Internationally, the CP-programs for elderly citizens have been 
successful and have low the risk of returning to the ED or readmission to the hospital (30-32). The CPs' have taken part in additional training for palliative care, and the new role has been found rewarding (29). Our study is the first known study where the clients of police also belong to the CNPs' patients. When the police patrol can avoid the ED with the drunken driver and take the driver directly to the police station, it benefits all participants. It is a safety matter for the others (staff and patients) in the ED.

The patient assessment at home is a unique situation, and the other family members (the spouse, the children) are playing an essential role in utilizing the patient's stay at home. Sometimes, the spouse or family member needs more support to cope with the responsibility (33-35). Patients are discharged from the hospital very early, and the family caregiver; sometimes, very old spouse receives responsibility, which could create emotional, physical, or financial burden (36). In our results, the CNPs were aware of some spouses' tiredness or how scared they could be when left at home with a frailty spouse. A recent study (37) wrote about caring for carers and how informal care may end to "spillover" effects when the pressure is too much left on the shoulders of the "healthier" spouse. In our study, the CNP pointed out that their patient assessment is now more holistic. Because they have more time, they can assess the patient and also consider the strengths of the other family members or the environmental risks "..now we can check the fridge, kitchen tables, and toilet.." before they try to find the solution. For them, the assessment, as a part of the provided care, has more dimensions than the recent primary survey as nurse-paramedic was. Into the CNPs' primary survey could be added more meaning for the F (ABCDEF approach), meaning Family or Friends. Sometimes the true stories or histories (how the patient is coping at home or during the last days) can be heard from someone else (from family member or friends) than from the patient himself.

This study illuminated how CNPs have a demanding way of providing care, including different roles, challenges and enablers. Our findings are consistent with several previous studies found many roles of paramedics as a clinician, health and social advocate, team member, educator, professional or reflective practitioner $(8,12,18)$. In our results, the CNPs took most a clinician or a strong advocacy role. While delivering care as a clinician, the CNPs use their knowledge, skills, and clinical judgment within the given scope of practice. Advocacy, as speaking on behalf of the patient (38), gives the CNP more comprehensive demands and challenges to find long-term solutions on how to able the patient to remain at home as long as possible or reach the right institute for patient's care need. According to our study, the participant CNPs does not have just a dual role between emergency and non-emergency service (13), hence at least quadruple role.

The independent work and broader possibilities to find solutions for the patient's needs can create powerless feelings. In our study, the CNPs described that with the independence work, sometimes comes the feeling of loneliness. These findings have implications for the organizational level because emotions like loneliness can cause exhaustion, distress, and lower job satisfaction. It is more potent if the employee feels that the work is without meaning. $(39,40)$. In our study, the CNPs pointed out that before, in the ambulance unit, there was always another person to share thoughts and decisions. Now the distances between the patients could be very long, and the visits can keep the CNP on the road all shift 
without seeing any other coworkers during the day. One rewarding and personally relevant and emotionally salient solution has been that the team-leaders meet the team members frequently (40) and actively share feedback keeping the members engaged in their integrated teams (41). However, paramedics have stated that they rarely received feedback from patient interactions (42). In our findings, on the contrary, the CNPs articulated that they receive direct and positive feedback almost daily, which is one of the needed forces, e.g., against the feeling of loneliness. Other remedies for the loneliness were the luxury of time with the patient, and the possibility for long-term solutions. As proposed in this study, the CNPs' possible to provide care is broad. However, with these results, the independent work creates challenges to consider also for management and organizational levels.

In this study, the CNPs highlighted the luxury of time as one of the cornerstones for the possibilities to provide functional care. The unhurriedness has been noticed as a significant enabler for the quality of the client-centered home care services $(35,43)$. Our results are consistent with this and signified the possibility of the CNP to settle down and spend more time to find more contributing solution for the patient's care needs. More time with the patient is also an essential motivator for CNP to work. The peaceful time with the patient able the home screening and ensure care considering the medical, social, and psychological assessment of the patient and the family ending with a better solution to cope at home. In a previous study, the paramedics indicated that the chance to spend more time assessing and understanding patients' unmet long-term needs is a disparity in their traditional values and requirements in ambulance units to identify life threats and to transport all patients without delay (42). Unhurriedness is a new component in the CNP's patient assessment and can take time for a former nurse-paramedic to learn to use it right to able to provide broad care.

The CNPs are familiar with patient assessment and providing small treatments or administrate medication. In this study, the CNPs' pointed out that they can rehearse their former nursing skills with the community nurses, e.g., wound therapy and urine catheterization. This finding is consistent with several previous studies investigating the multidisciplinary practice in action and highlighting the importance of health professionals to recognize the needs of informal training with each other $(44,45)$. When rehearsing e.g., with community nurses, the CNPs have the possibility for updated information. They are training relevant in the context of work practice and, at the same time, inform and discuss the CNPs' role with allied healthcare workers.

Our findings pointed out that one of the most necessary skills for the CNP was the patient assessment by phone. After similar results, some institutes have added this 'phone work/telemedicine' into the community paramedics' tailored training (46). The effectiveness of a phone assessment has been highlighted in previous research. It showed that one-third of the callers to the triage nurse were satisfied when they got care instructions or guidance to social and healthcare services (47). Furthermore, this telecare offers new possibilities for patients, especially in rural areas, and for all healthcare workers to be able to help and advice citizens safely by phone, e.g., like during outbreaks of contagious diseases (48). Our results are consistent with these findings. The CNP used the phone for patient assessment when 
confirming the safety of the call out by calling beforehand to the patient or the home care provider to verify the patient's care needs, prioritize the care, and consult.

All participants highlighted the diversity of multi-agency collaboration. Collaboration has been defined as one of the keys to the success of the Community Paramedicine programs $(5,49)$. The CNPs spoke about the multidisciplinary team and its social and cultural context with the possibilities to learn from each team member. In the community paramedicine teams have worked midwives (44), pharmacists (50), or social workers (51). Our results show the team is growing with the other EMS providers, the staff from ED, the home care providers, the psychiatric nurses, police, the personal safety responders, and the physicians. The unofficial "morning cuppa" visits, informal and formal meetings with other team members, are essential ways to get the right information and build up the appropriate expectations about the collaboration (52). These findings are consistent with our results, were the CNPs' were worried about the right information about their sphere of practice. They felt that collaboration could be very sensitive when different professions work on the same 'playground.' The rumors or expectations can easily create wrong perceptions. The CNP -models contribute to the healthcare system. However, healthcare management and organization could build the base with the right information where the boundaries of different professions are known, but each role and responsibilities are clear.

In our study emerged the management challenges for the system and the organization levels. The interviewees specified the challenges with the planning, management, reimbursement, and the delivering of the patient's health information between different organizations. Previous studies $(9,14,53,54)$ have also resulted in the challenges of the funding CP programs and the targeted reimbursement of those services. EMS services have predominantly focused on the transport of patients for emergent conditions. The concept of a "treat and referral" or a "treat and release" service is not built into the traditional EMS payment model. These innovative financial models for non-emergency care services need consideration at the federal level.

The change from the work as a paramedic in the ambulance unit into the one-person community paramedic unit creates challenges but has advantages. The dimensions of the new sphere of practice have essential influences on health care professionals' job satisfaction, work motivation, and wellbeing. Furthermore, it offers a needed partnership to allied health and safety professions in prehospital care. More research is needed considering the role, foci, and perceptions of the allied health and safety professions in how they see the future of Community Paramedicine.

\section{Limitations}

This study is not without limitations. First, the study was conducted in three Finnish HDs, which, although diverse, is not representative of all CNP models. Therefore, the results, as in ethnographic research, represent an interpretation of the observations, experiences, and stories. Possibly everything was not captured during the observation periods or with the interviews. However, the principal researcher (TR) moved between HDs for the observation periods to address this. Second, the use of a purposeful 
sampling may lead to bias (21). However, this sampling ensured that the interviewees have the relevant background.

Third, the data analysis and coding were performed by a single researcher who was also an experienced emergency nurse-paramedic. However, the researcher's background allows the use of the emic perspective to understand the insider's perceptions. Emic perspective is essential in an ethnographic study for a researcher to explain events from the participant's point of view (21). The long time with the CNPs gave time to the interviewed and the researcher to elicit the views. The authors discussed the quotes avoiding presenting raw data without analysis, remembering that also the quotes of the participants in this study are not raw data but purposefully selected by the researchers.

\section{Conclusion}

This descriptive ethnographic research of Finnish CNPs provides insight into how the CNPs and allied health care providers perceive the CNPs' sphere of practice. This study found that the essential elements of the CNPs' practice are the CNPs' way of thinking, the broad group of patients, the dimensions of providing care, the diversity of multi-agency collaboration and management challenges.

The analysis showed that the CNP model has some new demands, but nurse-paramedics need to take back in use also some old skills and competencies. The CNP's caring process is broader than the EMS process, and the role has many aspects from health care and social services integrating several external factors. A CNP has a vital role and broad scope to play in primary health care, a well-needed contribution to health and social care services. Results from this study indicate new knowledge from community paramedicine providers to all health care providers, policymakers, and educators to create, enable, and maintain a new integrated model in the primary care setting.

Further research is needed to investigate the alternative care pathways for the patients' and families' health and social care needs and outcomes, the choices for the CNP's decision making around nontransportation, and the outcome from the patients and the families.

\section{Abbreviations}

ED Emergency Department

EMS Emergency Medical Services

CNP Community Nurse-Paramedic

CP Community Paramedicine

\section{Declarations}

\section{Ethics approval and consent to participate}


All participants provided informed written consent after reading a Participant Information Form. The research protocol was approved by The Regional Ethics Committee of Tampere University Hospital (Reference Number: R19008H) and by the participated Hospital Districts' Research Boards and by the local EMS managers. The notifications to the patient data registrars at the Central Hospitals was undertaken when the study began. All the data has treated confidentially and with full disclosure, according to the Declaration of Helsinki in 1995.

\section{Consent for publication}

Not applicable

\section{Availability of data and materials}

The literature sources used to contribute to our conclusions are outlined within the manuscript. The interview data and the data from the field notes are not made publicly available due to them containing information that could risk the confidentiality of our participants.

\section{Competing interests}

The authors declare that they have no competing interests.

\section{Funding}

The study was funded by the Foundation of Research of Tampere University Applies Sciences/Finland.

\section{Authors' contributions}

$\mathrm{TR}, \mathrm{MK}$, and $\mathrm{KJ}$ conceived of the study with all authors contributing to its design. TR collected the data and led the analysis of data, with the support of $\mathrm{KJ}$ and MK. TR led on drafting the manuscript with input from KJ, ET, MK, and EP. All authors have critically reviewed and approved the final version of the manuscript.

\section{Acknowledgements}

The authors would like to thank the EMS providers and community nurse-paramedics involved in this study.

\section{Author details}

${ }^{1}$ Faculty of Social Sciences, Health Sciences, Tampere University, Kuntokatu 3, 33520 Tampere, Finland

${ }^{2}$ General Administration, Pirkanmaa Hospital District, 33014 Tampere University, Finland

${ }^{3}$ General Administration, The Hospital District of South Ostrobothnia, 60220 Seinäjoki, Finland 
4 Dean's Unit School of Health Sciences, Western Sydney University, Locked Bag 1797, Penrith 2750, NSW, Australia

QUniversity of Turku, Department of Nursing Science, Joukahaisenkatu 3-5, 20520 Turku, Finland

\section{References}

(1) Quality in Primary Health Care. Geneva, Switzerland: WHO; 2018.

(2) Valentijn PP, Schepman SM, Opheij W, Bruijnzeels MA. Understanding integrated care: a comprehensive conceptual framework based on the integrative functions of primary care. International journal of integrated care 2013;13(1):e010.

(3) WHO Home care across Europe. 2012; Available at: http://www.euro.who.int/en/publications/abstracts/home-care-across-europe.-current-structure-andfuture-challenges-2012. Accessed 15.1., 2020.

(4) Agarwal G, Angeles R, Pirrie M, Marzanek F, Parascandalo J, McLeod B, et al. Evaluation of a community paramedicine health promotion and lifestyle risk assessment program for older adults who live in social housing: a cluster randomized trial. Canadian Medical Association Journal 2018;190(21):E638-E647.

(5) Rasku T, Kaunonen M, Thyer E, Paavilainen E, Joronen K. The core components of Community Paramedicine - integrated care in primary care setting: a scoping review. Scandinavian Journal of Caring Sciences 2019 Sep;33(3):508-521.

(6) Dainty KN, Seaton MB, Drennan IR, Morrison LJ. Home Visit-Based Community Paramedicine and Its Potential Role in Improving Patient-Centered Primary Care: A Grounded Theory Study and Framework. Health services research 2018 Mar 15,(53 (5)):3455-3470.

(7) Bigham BL, Kennedy SM, Drennan I, Morrison LJ. Expanding Paramedic Scope of Practice in the Community: A Systematic Review of the Literature. Prehospital Emergency Care 2013 Jul 1;17(3):361372.

(8) O'Meara PF, Tourle V, Stirling C, Walker J, Pedler D. Extending the paramedic role in rural Australia: a story of flexibility and innovation. RURAL REMOTE HEALTH 2012 Apr;12(2):1-13.

(9) Nolan M, Gale N, Ruest M, Emon W, McNab K, Clock D, et al. Paramedic Referral Toolkit. Ontario Association of Community Care Acess Centres 2015:1-38.

(10) Abrashkin KA, Washko J, Zhang J, Poku A, Kim H, Smith KL. Providing Acute Care at Home: Community Paramedics Enhance an Advanced Illness Management Program-Preliminary Data. Journal of the American Geriatrics Society 2016;64(12):2572-2576. 
(11) Patterson DG, Coulthard C, Garberson LA, Wingrove G, Larson EH. What Is the Potential of Community Paramedicine to Fill Rural Health Care Gaps? Journal of Health Care for the Poor and Underserved 2016;27(4A):144-158.

(12) Brydges M, Denton M, Agarwal G. The CHAP-EMS health promotion program: a qualitative study on participants' views of the role of paramedics. BMC health services research 2016;16(1):435.

(13) Agarwal G, Angeles R, Pirrie M, Marzanek. F, McLeod B, Parascandalo J, et al. Effectiveness of a community paramedic-led health assessment and education initiative in a seniors residence building: the Community Health Assessment Program through Emergency Medical Services (CHAP-EMS). BMC Emergency Medicine 2017 Jan 1;17(8):1-8.

(14) Kizer K, Shore K, Moulin A. Community paramedicine: A promising model for integrating emergency and primary care. 2013; Available at:

https://cloudfront.escholarship.org/dist/prd/content/qt8jq9c187/qt8jq9c187.pdf. Accessed 14.11., 2019.

(15) Choi BY, Blumberg C, Williams K. Mobile Integrated Health Care and Community Paramedicine: An Emerging Emergency Medical Services Concept. Ann Emerg Med 2016;67(3):361-366.

(16) Ministry of Social Affairs and Health. Finnish Health Care Act . 2010; Available at: https://www.finlex.fi/fi/laki/kaannokset/2010/en20101326.pdf. Accessed 15.4., 2019.

(17) Ministry of Social Affairs and Health. Sosiaali- ja terveysministeriön asetus ensihoitopalvelusta (Decrees of Emergency Medical Services) . 2017; Available at: https://www.finlex.fi/fi/laki/alkup/2017/20170585. Accessed 20.4., 2019.

(18) Tavares W, Bowles R, Donelon B. Informing a Canadian paramedic profile: framing concepts, roles and crosscutting themes. BMC health services research 2016 Sep 7;16(1):477.

(19) Geertz C. The interpretation of cultures. Third edition ed. New York: Basic Books; 1973.

(20) Hammersley M. What is ethnography? Can it survive? Should it? Ethnography and education 2017;13(1):1-17.

(21) Holloway I, Galvin K. Ethnographia. Qualitative Research in Nursing and Healthcare United Kingdom: Wiley Blackwell; 2017. p. 159-179.

(22) Thomson D. Ethnography: a suitable approach for providing an inside perspective on the everyday lives of health professionals. International Journal of Therapy and Rehabilitation 2011;18(1):10-17.

(23) Clark P, Bowling A. Quality of everyday life in long stay institutions for the elderly. An observational study of long stay hospital and nursing home care. Social Science \& Medicine 1990;30(11):1201-1210. 
(24) Elo S, Kyngäs H. The qualitative content analysis process. Journal of Advanced Nursing 2008;62(1):107-115.

(25) Cavanagh S. Content analysis: concepts, methods and applications. Nurse researcher 1997;4(3):516.

(26) Sandelowski M. Theory unmasked: The uses and guises of theory in qualitative research. Research in Nursing \& Health 1993;16(3):213-218.

(27) Steeps RJ, Wilfong DA, Hubble MW, Bercher DL. Emergency Medical Services Professionals' Attitudes About Community Paramedic Programs. The western journal of emergency medicine 2017 Jun;18(4):630-639.

(28) Lau HS, Hollander MM, Cushman JT, DuGoff EH, Jones CMC, Kind AJH, et al. Qualitative Evaluation of the Coach Training within a Community Paramedicine Care Transitions Intervention. Prehospital Emergency Care 2018 Jul 4;22(4):527-534.

(29) Jensen JL, Travers AH, Marshall EG, Leadlay S, Carter AJE. Insights into the Implementation and Operation of a Novel Paramedic Long-term Care Program. Prehospital Emergency Care 2014 Jan $1, ; 18(1): 86-91$.

(30) Lee JS, Verbeek PR, Schull MJ, Calder L, Stiell IG, Trickett J, et al. Paramedics assessing Elders at Risk for Independence Loss (PERIL): Derivation, Reliability and Comparative Effectiveness of a Clinical Prediction Rule. CJEM 2016;18(2):121-132.

(31) Larsson G, Ziegert K, Holmen A. Early prehospital assessment of non-urgent patients and outcomes at the appropriate level of care: A prospective exploratory study. International Emergency Nursing 2017 May $1,32(1): 45-49$.

(32) Agarwal G, Angeles R, Pirrie M, McLeod B, Marzanek F, Parascandalo J, et al. Reducing 9-1-1 Emergency Medical Service Calls By Implementing A Community Paramedicine Program For Vulnerable Older Adults In Public Housing In Canada: A Multi-Site Cluster Randomized Controlled Trial. Prehospital Emergency Care 2019 Sep 3,23(5):718-729.

(33) Hämeenniemi J, Lamminen M, Paavilainen E, Kylmä J, Leikkola P. Pariskuntien kokemuksia sairaalan ulkopuolisesta ensihoidosta/Experiences of the prehospital emergency care among couples. Hoitotiede 2017 Jan 1;29(1):37-50.

(34) Paavilainen E, Mikkola R, Salminen-Tuomaala M, Leikkola P. Counseling patients and family members in out-of-hospital emergency situations: a survey for emergency staff. BMC nursing 2017;16(1):11.

(35) Sanerma P, Paavilainen E, Åstedt-Kurki P. Home care services for older persons. The views of older persons and family members: A realistic evaluation. International Journal of Older People Nursing 
2020;15(1):e12281-n/a.

(36) Vaartio-Rajalin H, Fagerström L. Professional care at home: Patient-centredness, interprofessionality and effectivity? A scoping review. Health \& Social Care in the Community 2019;27(4):e270-e288.

(37) Dixon P, Round J. Caring for Carers: Positive and Normative Challenges for Future Research on Carer Spillover Effects in Economic Evaluation. Value in Health 2019;22(5):549-554.

(38) Kalaitzidis E, Jewell P. The Concept of Advocacy in Nursing: A Critical Analysis. The health care manager 2020;39(2):77-84.

(39) Santas G, Isik O, Demir A. The effect of loneliness at work; work stress on work alienation and work alienation on employees' performance in Turkish health care institution. South Asian Journal of Management Sciences 2016;10(2):30-38.

(40) Arslan A, Yener S, Schermer JA. Predicting Workplace Loneliness in the Nursing Profession. Journal of nursing management 2020 Feb 27,(28 (3)):710-717.

(41) Jones J, Bion J, Brown C, Willars J, Brookes O, Tarrant C. Reflection in practice: How can patient experience feedback trigger staff reflection in hospital acute care settings? Health Expectations 2020;23(2):396-404.

(42) Brydges M, Spearen C, Birze A, Tavares W. A Culture in Transition: Paramedic Experiences with Community Referral Programs. CJEM 2015;17(6):631-638.

(43) Barratt J, Thomas N. Nurse practitioner consultations in primary health care: a case study-based survey of patients' pre-consultation expectations, and post-consultation satisfaction and enablement. Primary health care research \& development 2018 Jul 17;20:1-8.

(44) Mulholland P, Barnett T, Spencer J. Interprofessional learning and rural paramedic care. Rural and remote health 2014;14(3):2821.

(45) Mulholland P, Barnett T, Woodroffe J. A grounded theory of interprofessional learning and paramedic care. Journal of Interprofessional Care 2020 Jan 2;34(1):66-75.

(46) Tariq A, Westbrook J, Byrne M, Robinson M, Baysari MT. Applying a human factors approach to improve usability of a decision support system in tele-nursing. Collegian 2017;24(3):227-236.

(47) Roivainen P, Hoikka MJ, Raatiniemi L, Silfvast T, Ala-Kokko T, Kääriäinen M. Telephone triage performed by nurses reduces non-urgent ambulance missions: A prospective observational pilot study in Finland. Acta anaesthesiologica Scandinavica 2020 Jan 2;(4)(64):556-563.

(48) Zhi Li, Moran P, Qingyuan Dong, Shaw RJ, Hauser K. Development of a tele-nursing mobile manipulator for remote care-giving in quarantine areas. ICRA 2017:3581-3586. 
(49) Pearson K, Shaler G. COMMUNITY PARAMEDICINE PILOT PROGRAMS: LESSONS FROM MAINE. Journal of Health and Human Services Administration 2017 Oct 1,;40(2):141-185.

(50) Crockett BM, Jasiak KD, Walroth TA, Degenkolb KE, Stevens AC, Jung CM. Pharmacist Involvement in a Community Paramedicine Team. Journal of Pharmacy Practice 2017;30(2):223-228.

(51) Campbell H, Rasmussen B. Riding Third: Social Work in Ambulance Work. Health \& Social Work 2012;37(2):90-97.

(52) Mulholland P, O'Meara P, Tourle V, Walker J, Stirling C. Multidisciplinary practice in action: the rural paramedic - it's not only lights and sirens. Journal of Emergency Primary Health Care 2009;7(2):46KB.

(53) Pearson K, Gale J, Shaler G. Community Paramedicine in Rural Areas: State and Local Findings and the Role of the State Flex Program. University of Southern Maine 2014;1.

(54) Zavadsky M, Hagen T, Hinchey P, McGinnis K, Bourn S, Myers B. Mobile Integrated Health Care and Community Paramedicine (MIH-CP). 2015; Available at: www.naemt.org/docs/defaultsource/community-paramedicine/naemt-mih-cp-report.pdf?sfvrsn=4. Accessed 9.9., 2018.

\section{Figures}

\section{Interview Guide}

- Main Question: How do you describe your new role as a CNP?

- Can you describe what has changed?

- Are there added or defaulted tasks since working as a nurse-paramedic?

- Has the co-worker team changed?

- What has changed since the beginning of your CNPmodel?

\section{Figure 1}

Interview Guide of Community nurse-paramedics 


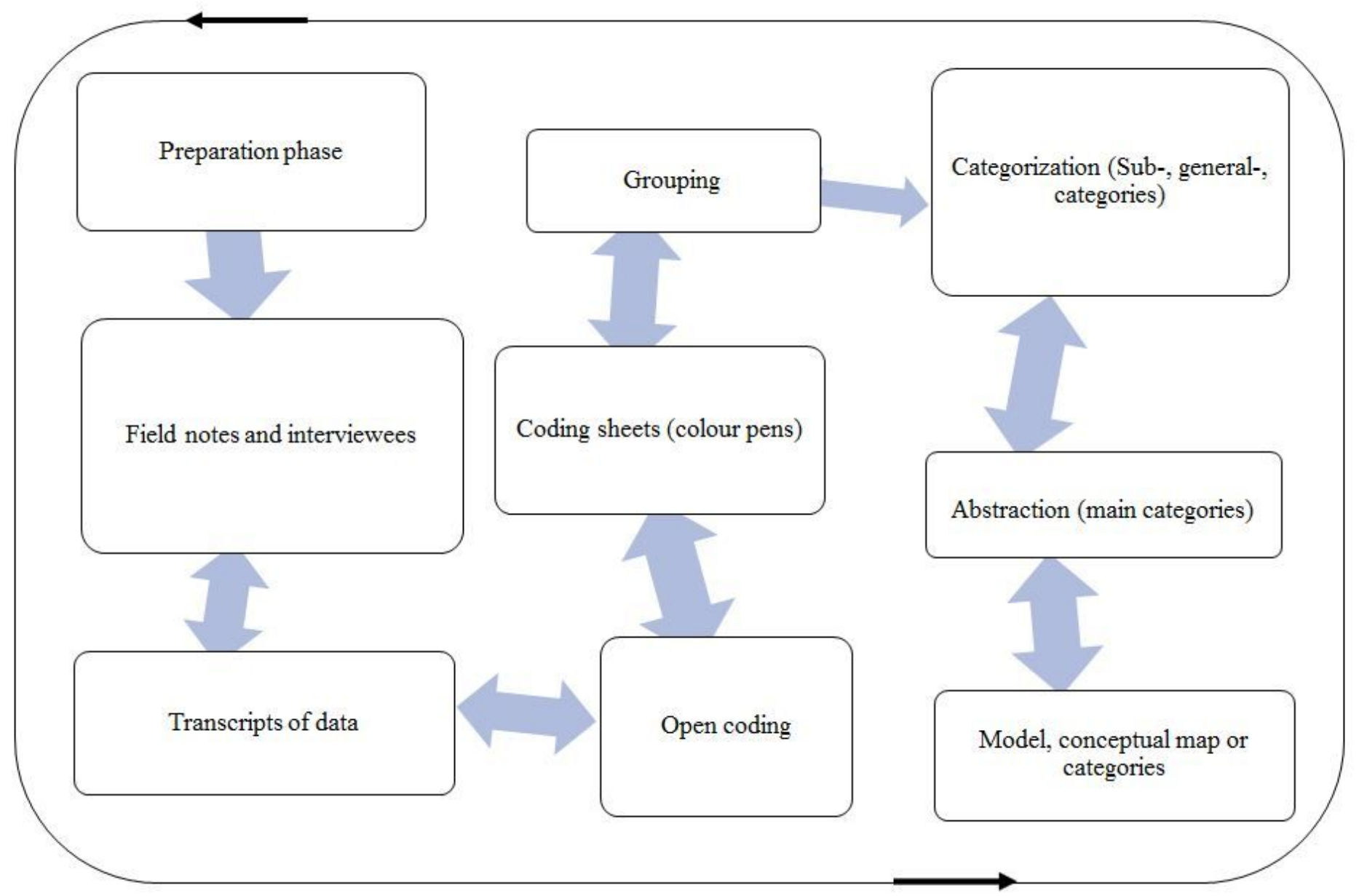

Figure 2

The phases in the inductive approach of the content analysis process Modified from Elo\&Kyngäs (2008)

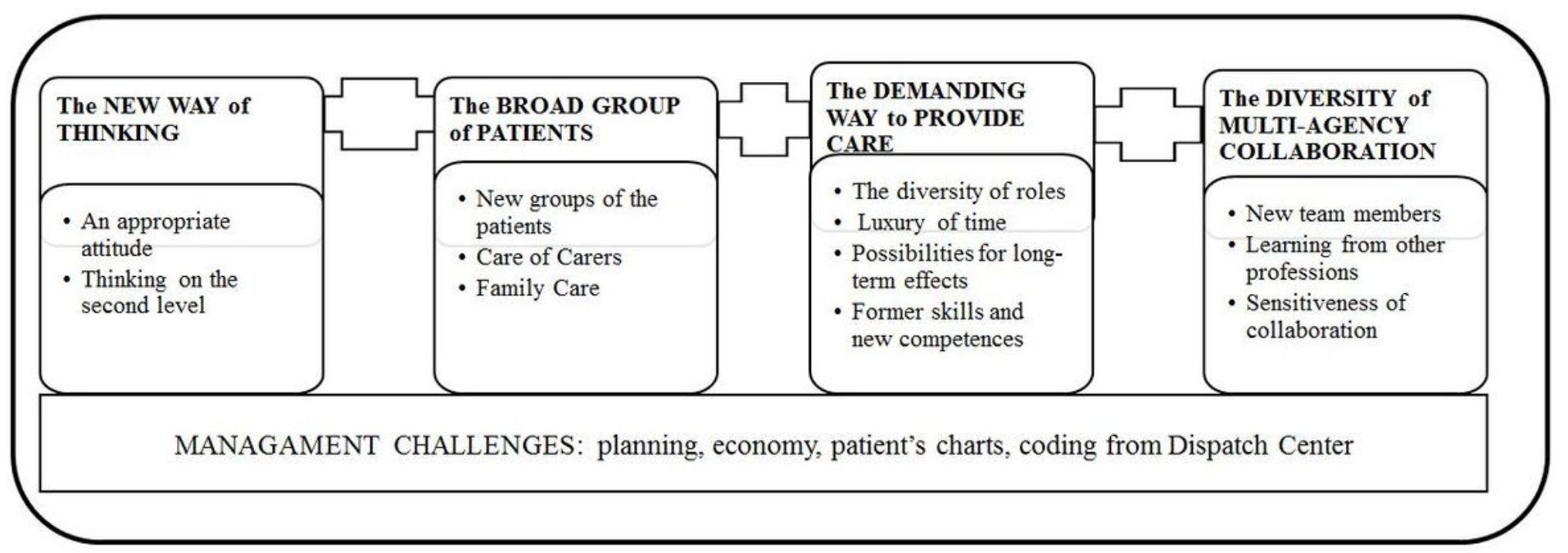

Figure 3

The Community nurse-paramedics' novel sphere of practice 


\section{Supplementary Files}

This is a list of supplementary files associated with this preprint. Click to download.

- COREQ32checklist.docx 